\title{
FERNANDO PESSOA e a construção do leitor heterônimo
}

Graça Paulino

Resumo

Este trabalho apresenta uma análise do processo de construção do leitor-modelo como mais um heterônimo de Fernando Pessoa em Fiç̧es do interlúdio.

\section{Abstract}

This paper analyses the model reader's construction processing as a heleronym of the poct Fernando Pessoa in Fiç̧os do interlidio.

Os heterónimos de Fernando Pessoa já foram exaustivamente analisados como-estratégias de produçăo poética.. Aliás, a abertura de espaços para a alteridade. numa polifonia que abarca não só as polemizações filosóficas, como também as formais, embora tenha constituído no início do século uma surpresa feliz para a crítica literária e para os leitores em geral, foi, com o decorrer do tempo, encontrando explicaçóes teóricas adequadas. Entre estas, encontra-se, sem dúvida, a relativização por que passou o conceito de identidade no contexto pós-moderno. O autor empirico, que costumamos chamar de autor oe carne e osso, nesse mesmo processo, deixaria de ser confundido a eu poético. que começaria, assim. 
em teoria literária, a ser considerado táo ficcional quanto qualquer narrador ou personagem de romance. Evidentemente, nem por isso alguém reprimiria hoje o impulso de arrepiar-se, ao ler certo poema de Ricardo Reis, escrito quinze dias antes da morte daquele Fernando Pessoa, homem de ossos, sonhos, conflitos e álcool que estamos reduzindo à mera condição de "autor empirico". Eis o poema:

Vivem em nós inümeros;

Se penso ou sinto, ignoro

Quem é que pensa e sente.

Sou somente o lugar

Onde se sente ou pensa.

Tenho mais almas que uma.

Há mais eus do que eu mesmo.

Existo todavia

Indiferente a todos.

Faço-os calar: eu falo.

Os impulsos cruzados

Do que sinto ou não sinto

Disputam om quem sou.

Ignoro-os. Nada ditam

A quem me sei: $\theta u$ 'screvo'.

Triste, sem dúvida, além de irónica, é essa retomada tardia de um poder de enunciação que nunca tinha faltado ao poeta. Ao tentar calar a diversidade do imaginário, em nome da razão univoca, a proposta é restabelecer a saúde, como sinónimo da ordem simbólica. Para a poesia, assim como para a salvação do corpo e da alma, tal tentativa é inútil. O poema não é dos melhores, e a vida se esvai sem remédio.

Maria Aliete Galhoz, num ensaio antigo, afirmou que

Fernando Pessoa não se despersonalizou verdadeiramente no sentido em que afirmou té-1o feito: "simulador" externo, pela facilidade de uma argumentafáo que desprezava, por the ser desnecessário o suporte de um real najo verbal. "mentiroso" de fora, por uma poténcia visionária que the permitia uma pluralidade de monólogos com suficiente imaglstica diferenciadora ${ }^{2}$.

Ora, não sei se de fato poderlamos considerar a existéncia dos heterónimos como opça do poeta singular por uma "pluralidade de monólogos". O problema nảo está, é claro, na "pluralidade". mas nos "monólogos". Escrito, porém, em 1960. como introdução à obra de FP publicada pela Editora Aguilar. 
esse texto de Galhoz ainda paga seu tributo ao new criticism, que considerava toda a poesia uma espécie de monólogo intransitivo, auto-suficiente, fechado em si mesmo.

Acontece que. a partir da década de 70 , foi repensado pela teoria o modo de existência da obra literária. E isso foi feito exatamente através do questionamento as propostas monológicas, que estavam centradas numa concepçáo de poesia como propriedade privada do autor. Eu me permitirei aqui retomar as idéias de Wolfgang Iser e de Umberto Eco sobre a presença, no próprio texto literário, da previsáo de papéis e funçōes para o leitor, configurando o que o primeiro denominou "leitor implicito", e, o segundo, "leitor-modelo".

Antes que alguém me pergunte o que terá isso a ver com Fernando Pessoa, explico que minha dúvida fundamental é a seguinte: teria o desdobramento em diferentes vozes-póticas correspondido ao desdobramento em diferentes modelos de toitores. isto é. podemos falar de fato da construção de leitores heterónimos, ou o processo se reduziu à instância de enunciação poética? Aliás, a questão é até um pouco mais complexa, se levarmos em conta a possibilidade de que o leitor modelado jamais corresponda a algum dos reflexos do autor. desempenhando exatamente as funçōes que este nảo podia ou nảo queria desempenhar.

Primeiro, analisemos a teoria. Na verdade, tanto Iser quanto Umberto Eco apenas radicalizaram, nos anos 70 , a concepção de linguagem que Bakhtin desenvolvera na mesma época em que vivia e poetava fernando Pessoa. Trata-se da consideração de que em cada ato de fala nunca se pode isolar uma voz, pois que a cada momento diversas vozes se cruzam numa mesma enunciação, derivando isso do fato de que a linguagem tem uma existência social, inevitavelmente social, e. assim sendo, inevitavelmente plural. Entre essas vozes, Bakhtin incluía as do interlocutor, transformando a interação verbal num processo próprio do fazer lingüístico. Näo me lembro de referéncias explicitas ao pensamento de Bakhtin, tanto em The implied reader. de Iser, quanto em Lector in fabula, de Umberto Eco. Insisto aqui nessa associação de idéias para mais uma vez desfazer o silêncio que cercou durante tanto tempo a obra do grande pensador russo, um socialista perseguido pelo stalinismo e ignorado pela América de Jakobson.

Umberto Eco, desde A obra aberta, de 1962, se voltou para questōes ligadas a interpretação dos textos literários. Entretanto, quando publica, em 1978, a obra intitulada Lector in fabula, assume um modelo textual que prevé estrategicamente as recepçōes possiveis, tomando estas como partes integrantes do texto. Embora afirme que, ao mesmo tempo em que dá crédito ao leitor ele cede à necessidade de controlá-lo, trocando o prazer do texto pelas razóes por que o texto poderia provocar prazer. 
há uma parte de Leclor in fabula na qual esse leitor Umberto Eco que teoriza sobre o leitor modelo de um conto mantém tão vivo - seu entusiasmo que nos leva a colocar em dúvida os limites racionalistas que o modelo pretende apresentar.

O ponto básico dessa teoria é a hipótese de que a produção de um texto inclui necessariamente estratégias capazes de postular a cooperação do leitor. James Joyce. por exemplo construiu seu leitor modelo como um "operador capaz de realizar: ao mesmo tempo: o maior número de leituras cruzadas, com muita habilidade asssociativa, e com uma enciclopédia de limites esfumados". Essa previsão pode ser inconsciente, como outros componentes de textos também o são. Entretanto, ao negar-se a trabalhar com intençōes do autor empirico. Umberto Eco opta por um leitor-modelo que reverte o processo, construindo também o autor modelo no momento da leitura. São movimentos cooperativos entre texto e leitor, entre leitor e texto, de tal forma mantidos num elo dialético que nem se sacrifica a intentio operis nem se ignora a intentio lectoris, sendo todo esse latim da responsabilidade de Umberto Eco

Uma séria restrição que se pode fazer a essa teoria passa pelas diferenças significativas entre as leituras de diferentes épocas. Postulados que estejam os movimentos do leitor. serão eles os mesmos para sempre? Evidentemente, Umberto Eco nảo teria coragem de responder que sim. A previsảo de leituras não se associa à definição do texto como um objeto pronto e acabado. Pelo contrário, é pelos implícitos e não-ditos que passa muito do trabalho do leitor, cujas entradas em cena poderão diferir enormemente. como combinatórias possiveis num subcódigo aberto. Entretanto, nem todas as combinatórias serāo possiveis. porque algumas deixarảo de ser cooperativas, e, então, qualquer proposta do texto deixará de ter importáncia, e a leitura não mais corresponderá, nesse caso, a interpretação, mas ao uso aleatório. Em suma, como afirma Umberto Eco em uma de suas obras mais recentes, de 1993, - Interpretação $\theta$ superinterprelação - "um texto é um dispositivo concebido para produzir seu leitor-modelo.(...)este leitor não é o que faz a 'única' conjectura 'certa'. Um texto pode prever um leitor-modelo com direito de fazer $n$ conjecturas."

Voltemos a lirica de Fernando Pessoa, que, aliás, se caracterizou como um poeta dramátıco escrevendo poesia lírica em Ficções do interlúdio. Na obra inteira do poeta há várias passagens em que um leitor é construldo explicitamente num processo de interlocução e de provocação planejadas. Todavia, em momento algum é mais explicitamente assumida a modelagem de um leitor que na "nota preliminar" de Mensagem. Nessa "nota". Pessoa associa o entendimento de simbolos a cinco qualidades do intérprete: simpatia, intuição. inteligência, compreensảo e graça. Em outras palavras. ele estava a exigir do leitor uma 
aproximaçåo emocionada, em vez do distanciamento, uma capacidade de estabelecer relaçóes e analogias, em vez do apego a detalhes e partes isoladas, uma enciclopédia, como a do leitor de Joyce, de limites intersemióticos esfumados, e, por fim. uma iluminação de caráter transcendental. Se a exigência dessa última qualidade se explica de maneira melhor localizada no texto mistico de Mensagem, as anteriores permitem que nós desejemos verificar sua pertinência com relação ao leitor-modelo de outras obras, tais como Cancioneiro e Fiç̧őes do interlúdio.

A exigéncia de simpatia, sendo esta contrária, segundo o próprio Fernando Pessoa, à leitura irónica e ao distanciamento crítico, defende uma relação catártica do leitor com sua poesia, - que, como sabemos, seria espantoso e quase inaceitável na maior parte dos poemas que compỏem Fiç̧ōes do Interlúdio. embora aparentemente viável na leitura do Cancioneiro. Entrefanto, mesmo nesta obra, o pretenso leitor em identificaça o catártica terá de dar conta, por exemplo, de uma reconstrução cética do Natal, e, ao lado de outro poema quase sentimentalista, que destaca o aconchego natalino dos lares na provincia, interpretar ainda um terceiro, que desloca a experiência da data para o nivel físico, material, neste incluindo ironicamente a própria ação de escrever. Se os tres poemas se contradizem. e se apenas um deles permite a catarse, percebemos que o leitor pretendido náo deve limitar-se a capacıdade de simpatia, mas deve também ser um bom intérprete de procedimentos irónicos, o que dele exige, sem dúvida, uma postura distanciada e critica. Leiamos os poemas que, embora conhecidos, merecem novo destaque neste nosso fim de ano de 1994.

\section{Natal}

Nasce um Deus. Outros morrem. A Verdade Nem veio nem se foi: o Erro mudou. Temos agora uma outra Eternidade. E era sempre melhor o que passou.

Cega, a Ciência a inútil gleba lavra. Louca, a fé vive o sonho de seu culto. Um novo deus é só uma palavra. Não procures nem crejas: tudo é oculto ${ }^{3}$.

Chove. E dia de Natal. Lá para o Norte é melhor: Há a neve que faz mal. $E$ o frio que ainda é pior. 
E toda a gente é contente Porque é dia de o ficar.

Chove no Natal presente. Antes isso que nevar.

Pois apesar de ser esse

- Natal da convenção. Quando o corpo me arrefece

Tenho o frio e Natal najo 4 .

Deixo sentir a quem quadra

E o Natal a quem o fez,

Pois se escrevo ainda outra quadra

Fico gelado dos pés.

(1930)

Natal... Na provincia neva.

Nos lares aconchegados.

Um sentimento conserva

Os sentimentos passados.

Coração oposto ao mundo.

Como a familia é verdade!

Meu pensamento é profundo.

'Stou só e sonho saudade.

E como é branca de graça

A paisagem que nāo sei.

Vista de trás da vidraça

do lar que nunca terei! ${ }^{5}$

Bem, se o modelo "simpático" de leitor nåo se sustenta sozinho no Cancioneiro, muito menos o fará nas produçóes heterônimas. Entretanto, há uma construção de leitor que se evidenciou nesse Fernando Pessoa ele mesmo (allás, que expressão absurda). Trata-se do leitor proposto em mutação, sem permanecer preso a uma atitude fixa, um leitor capaz de alterar seus esquemas de recepção de acordo com cada momento da experiência poética que vive. Mas năo será este, afinal, vocês perguntariam, o leitor modelo de toda a poesia, independente de quem a escreva? Creio que será este pelo menos o modelo de leitor que se mantém em toda a poesia de Fernando Pessoa assumida por Alberto Caeiro, Ricardo Reis e Álvaro de Campos.

Por via das dúvidas, tentarei responder a primeira pergunta: toda poesia que se preza exigiria, como parte de sua constituição, um leitor capaz de transitar da fé à descrença, da ironia ao sentimentalismo. enfim, de um extremo a outro da série 
de atitudes que se poderia prever para ele no momento da produção poética?

Minha resposta tende a ser a de que a poesia tradicionalmente exige menos, e a poesia de nosso século talvez exija coisa um pouco diferente. A partir da constituição de uma poética da alogicidade. com seu aparato simbolico refratário. ligado à expressão do inconsciente, um leitor-modelo moderno de poesia é construldo por um enorme conjunto de textos. Desse leitor se exige um conhecimento da linguagem como subcódigo distanciado do padrảo, assim como um amplo conhecimento prévio de mundo e poesia necessário à interpretação de processos metafóricos e metalinguísticos complexos. A poesia de Fernando Pessoa, ainda que se mantenha nos limites do discursivo, exige um modelo de leitor semelhante, mas radicaliza especialmente sua modelagem de recepção devido à sua inclinação filosófica dominante.

Embora moderado com relação às quebras do padrāo sintático, nosso poeta, do ponto de vista filosófico, prevê um leitor que deve possuir especial habilidade de reflexáo e de questionamento do mundo e da vida convencionais, tudo isso ligado a abertura suficiente para duvidar de valores socialmente dominantes, mitos sociais, inclusive o do sujeito enquanto identidade pronta e monolítica, ou o da vida defendida a qualquer custo.

A esse respeito, é exemplar o poema que comeca perguntando ao leitor: "Se te queres matar, por que nảo te queres matar?" A ironia destrói todos os processos ilusórios que o sistema social associa à existência humana, especialmente esse que se baseia no mito da permanéncia do sujeito. Objeto de usos na alteridade inevitável, a multiplicidade de papéis do sujeito se desenha em mediocridades que, por si sós, tornariam a vida ridicula e insuportável. O poeta e seu leitor, ambos acuados pelo senso comum, escapam graças à propria criação e recriação poéticas.

Um lingüista, Grice, afirmou que, para o ouvinte prestar atençao à fala do outro, exige: seja verdadeiro, seja breve, seja claro, seja relevante. Em literatura dispensamos tudo, menos a relevãncia, e é exatamente essa releváncia a um só tempo poética e filosófica que o texto de Fernando Pessoa mantém para seu leitor-modelo contemporâneo.

Segundo Rorty. um pragmatista que polemiza com Umberto Eco. "um texto só nos é útil quando ajuda a mudar nossos propósitos, e, assim. a mudar nossas vidas." Vendo pela perspectiva oposta, em defesa da leitura comprometida com um trabalho interativo e não com o mero uso do texto, eu diria que só nos metemos na aventura da interpretaçăo em nome dessa mudança. E o leitor de Fernando Pessoa se constrói como mais um heterónimo exatamente porque se constrói nesse espaço do 
mutável, nessa possibilidade de transformação constante. proposta de vida incómoda, relativa e sem paz. A opção pelo diálogo chega ao extremo de não permitir um leitor semelhante. irmão nas horas boas, com que se partilha alguma paz, algum EU centrado e forte. "indiferente a todos".

Mas a intenção da obra, nesse caso, se encontra idealmente com a intenção do leitor, por paradoxal que pareça um encontro ocorrendo em condiçōes tão dificeis e desafiadoras. É que, para conseguir ler em condiçōes de felicidade a poesia de Fernando Pessoa, o leitor também tem de pretender questionar o sono tranquilo das mediocridades áureas, o leitor também tem de pretender encarar suas metamorfoses, suas fragilidades e suas ambigaidades sem conta. Digamos que uma reflexão poética radical como a de Pessoa exige no mínimo isso de seu leitor-modelo, de tal forma que suąs encarnaçỏes reais - nós enfrentamos com gosto esse processo interativo. pois do contrário abandonariamos a leitura, ou a transformariamos em pretexto para curtições particulares e diálogos impossiveis, isto é, nem estariamos aqui agora.

Por estarem aqui, e por me acompanharem de algum modo nesse passeio pelo bosque, agradeço-lhes muito, e peço desculpas pelas inevitaveis demoras e hesitações. Lupus in fabulo.

\section{Notas}

1. PESSOA. Fernando. Obra pótica. Rio de Janeiro: Aguilar. 1965. p. 291

2. Op. cit. p. 41

3. Op. cit. p. 139

4. Op. cit. p. 148

5. OD. cit p. 154 